\title{
The Outcomes of Switching from Short- to Long- Term Intravitreal Corticosteroid Implant Therapy in Patients with Diabetic Macular Edema
}

\author{
Sara Vaz-Pereira ${ }^{a, b}$ João Paulo Castro-de-Sousac-e David Martins ${ }^{f}$ \\ Joaquim Prates Canelas ${ }^{a, b}$ Pedro Reis ${ }^{g}$ António Sampaio $^{\text {h }}$ Helena Urbano $^{\mathrm{i}}$

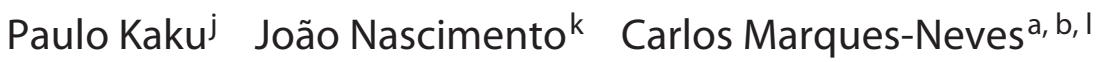 \\ a Department of Ophthalmology, Centro Hospitalar Universitário de Lisboa Norte, EPE - Hospital de Santa Maria, \\ Lisbon, Portugal; ${ }^{b}$ Department of Ophthalmology, Faculdade de Medicina, Universidade de Lisboa, Lisbon, \\ Portugal; ' Department of Ophthalmology, Centro Hospitalar de Leiria, Leiria, Portugal; ${ }^{d} \mathrm{CICS}-\mathrm{UBI}$, Health Sciences \\ Research Centre, University of Beira Interior, Covilhã, Portugal; ${ }^{e}$ Faculty of Health Sciences, University of Beira

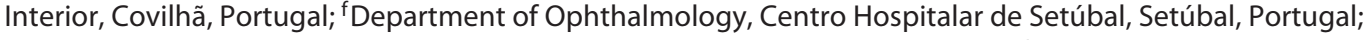

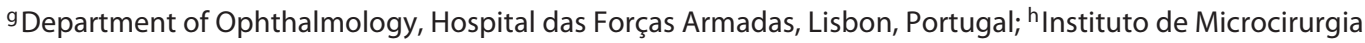 \\ Ocular, Lisbon, Portugal; ' Department of Ophthalmology, Centro Hospitalar de Lisboa Ocidental - Hospital Egas \\ Moniz, Lisbon, Portugal; jDepartment of Ophthalmology, Hospital da Cruz Vermelha Portuguesa, Lisbon, Portugal; \\ k' Instituto de Retina de Lisboa, Lisbon, Portugal; 'ALM Oftalmolaser, Lisbon, Portugal
}

\section{Keywords}

Visual acuity - Diabetic macular edema · Fluocinolone acetonide intravitreal implant · Safety · Real-world study

\begin{abstract}
Background: First-line treatment for diabetic macular edema (DME) is usually with antivascular endothelial growth factor agents, followed by intravitreal corticosteroids as a second-line treatment option. Long-term corticosteroids may offer quality of life and effectiveness benefits over shortterm implants. Objectives: To evaluate outcomes of patients with persistent or recurrent DME who switched from a shortterm (dexamethasone) to a long-term (fluocinolone acetonide, FAc) corticosteroid intravitreal implant in a real-world setting. Methods: This is a retrospective study in 9 Portuguese centers. An FAc intravitreal implant was administered
\end{abstract}

\begin{tabular}{ll}
\hline KARGER & $\begin{array}{l}\text { (c) } 2019 \text { The Author(s) } \\
\text { Published by S. Karger AG, Basel }\end{array}$ \\
E-Mail karger@karger.com & This article is licensed under the Creative Commons Attribution- \\
www.karger.com/ore & $\begin{array}{l}\text { NonCommercial-NoDerivatives 4.0 International License (CC BY- } \\
\text { NC-ND) (http://www.karger.com/Services/OpenAccessLicense). } \\
\text { Usage and distribution for commercial purposes as well as any dis- } \\
\text { tribution of modified material requires written permission. }\end{array}$
\end{tabular}

according to product labeling. Effectiveness outcomes were mean change in visual acuity (VA; ETDRS letters), central retinal thickness (CRT; $\mu \mathrm{m})$, and macular volume $\left(\mathrm{MV} ; \mathrm{mm}^{3}\right)$. The safety outcome was mean change in intraocular pressure (IOP; $\mathrm{mm} \mathrm{Hg}$ ). All were analyzed at months 1 and 3, and then quarterly until month 24 after implantation. Results: Fortyfour eyes from 36 patients were analyzed. Mean duration of DME was $3.3 \pm 1.9$ years, and mean follow-up was 8 months. From baseline following FAc implantation, VA increased significantly at months 1 and 6 (mean +6.82 and +13.02 letters, respectively; $p=0.005$ ), and last observation carried forward (LOCF; mean +8.3 letters; $p=0.002$ ). CRT improved significantly at months 1 and 6 (mean -71.81 and $-170.77 \mu \mathrm{m}$, respectively; $p=0.001$ ), and LOCF (mean $-121.46 \mu \mathrm{m} ; p=$ $0.001)$. MV was consistently, but not significantly, decreased from baseline to LOCF (mean $-0.69 \mathrm{~mm}^{3} ; p=0.062$ ). The mean change in IOP was -0.25 and $+0.88 \mathrm{~mm} \mathrm{Hg}$ at months
Sara Vaz-Pereira, MD

Department of Ophthalmology, Hospital de Santa Maria

Avenida Professor Egas Moniz

PT-1649-035 Lisbon (Portugal)

E-Mail saravazpereira@gmail.com 
1 and 6 , respectively $(p=0.268)$, and $+1.86 \mathrm{~mm} \mathrm{Hg}$ at LOCF $(p=0.036)$. Increases were controlled with topical medication in most cases. Conclusions: The FAc intravitreal implant is effective in patients previously treated with short-term corticosteroid implants. Thus, after a suboptimal response to antiangiogenics or a short-term corticosteroid, a single FAC implant may be considered an effective and tolerable treatment that can improve long-term outcomes for patients with sight-threatening DME.

C) 2019 The Author(s)

Published by S. Karger AG, Basel

\section{Introduction}

Diabetic macular edema (DME) is the most common cause of vision loss in patients with diabetic retinopathy [1]. With the growing prevalence of diabetes, an aging population, and the increased life expectancy of individuals with diabetes, the prevalence of DME is expected to rise [2]. In the Diabetic Retinopathy Barometer Study of 4,340 adults from 41 countries across 5 continents, the global prevalence of DME was 7.6\%. Prevalence rates were highest in the Eastern Mediterranean region (11.0\%) and lowest in the Western Pacific region (5.6\%), and prevalence increased with age and time since diagnosis [3]. DME significantly impacts a patient's quality of life because functional ability declines at higher levels of visual impairment [4], and an estimated almost two-thirds of individuals with DME experience limitations in performing daily activities [5].

Without treatment, nearly half of all patients who develop DME will lose 2 or more lines of visual acuity (VA) within 2 years [6]. Thus, early diagnosis and effective treatment of DME are essential in preventing visual impairment and avoiding vision loss [4]. Current treatment guidelines generally recommend antivascular endothelial growth factor (anti-VEGF) therapy as first-line treatment for central-involving DME, with corticosteroids as a recommended second-line treatment option [7-9].

Randomized controlled trials (RCTs) of anti-VEGF therapy administered by intravitreal injection have shown favorable VA and retinal morphology outcomes when used as first-line therapy in patients with DME, with the best results generally achieved with monthly or bimonthly dosing regimens [10]. However, not all patients demonstrate optimal visual outcomes, and up to half show persistent edema after use of anti-VEGF therapy alone. This may be explained by suboptimal responses to therapy or suboptimal delivery of the medication. Indeed, in the former case, if ineffective treatment is resumed, or the patient is left untreated, the risk of vision deteriorating increases [11]. In the latter case, ophthalmologists tend to prescribe anti-VEGF therapy as first-line treatment for DME in real-world settings [12]; however, their administration is less frequent than in anti-VEGF RCTs $[10,11]$.

Intravitreal injections of corticosteroids have been shown to be beneficial in the treatment of patients with DME $[13,14]$. Corticosteroids have a dual effect as they inhibit the inflammatory response to a variety of inciting agents and reduce levels of VEGF: both of which play key roles in the pathophysiology of DME [15-19]. The corticosteroid fluocinolone acetonide (FAc), administered as an intravitreal implant (ILUVIEN $190 \mu \mathrm{g}$ intravitreal implant in applicator; Alimera Sciences Limited, Aldershot, $\mathrm{UK})$, is indicated in Europe for the treatment of vision impairment associated with chronic DME in patients considered to be insufficiently responsive to available therapies (i.e., persistent or recurrent DME despite prior treatment) $[20,21]$. Each implant contains $190 \mu \mathrm{g}$ of FAc with a daily release rate of $0.2 \mu \mathrm{g}$ for up to 3 years.

Past studies have documented the effectiveness and tolerability of the implant after mainly first-line treatment with anti-VEGF therapies [22]. The objective of the current study was to assess the effectiveness and safety of the FAc intravitreal implant, in patients with persistent or recurrent DME despite treatment, after treatment with at least 1 dexamethasone implant.

\section{Materials and Methods}

Study Design

This was a retrospective, multicenter study of patients with DME treated with an FAc intravitreal implant, who attended one of 9 Portuguese public hospitals or private health clinics.

\section{Patients and Study Procedures}

For inclusion in the study, patients were required to have persistent or recurrent DME. Patients were judged to be insufficiently responsive to anti-VEGF treatment (or were unsuitable for antiVEGF therapy) and were then treated with at least 1 dexamethasone implant and afterwards considered for treatment with an FAc intravitreal implant. Exclusion criteria were the presence of macular edema secondary to causes other than diabetic retinopathy, previous treatment with an FAc intravitreal implant, uncontrolled ocular hypertension, diagnosis of moderate-to-severe glaucoma, and the presence of active or acute intraocular inflammation or infection. A single FAc intravitreal implant was injected in the affected eye of patients according to product labeling [20].

Outcomes

Outcomes were analyzed at months 1 and 3, and then quarterly until month 24 after receiving the FAc intravitreal implant. Effectiveness evaluations included mean change in VA, mean 
Table 1. Summary of patient demographics (44 eyes of 36 patients) and baseline characteristics

\begin{tabular}{ll}
\hline Patients & \\
Age, years & $69.2 \pm 7.4$ \\
Sex & 65.9 \\
$\quad$ Male & 34.1 \\
$\quad$ Female & \\
\hline Eyes & $3.3 \pm 1.9$ \\
Duration of DME, years & \\
Lens condition & 31.8 \\
$\quad$ Phakic & 63.6 \\
$\quad$ Pseudophakic & 4.5 \\
$\quad$ Aphakic & \\
Previous vitrectomy & 22.7 \\
$\quad$ Yes & 77.3 \\
$\quad$ No & \\
Previous treatment for DME & 18.6 \\
$\quad$ Bevacizumab & 53.5 \\
$\quad$ Ranibizumab & 25.6 \\
$\quad$ Aflibercept & 37.2 \\
$\quad$ Triamcinolone & 100.0 \\
$\quad$ Dexamethasone & \\
Concomitant IOP-lowering & $8.0(18.2)$ \\
$\quad$ medication use, $n$ (\%) & $8.0(1.0-23.0)$ \\
Mean (range) follow-up, months & \\
\hline
\end{tabular}

Values are mean \pm SD or $\%$ unless otherwise indicated. DME, diabetic macular edema; IOP, intraocular pressure; SD, standard deviation.

change in central retinal thickness (CRT), and mean change in macular volume (MV). Safety evaluations included mean changes in intraocular pressure (IOP) and times to IOP medication as well as cataract extraction.

\section{Data and Statistical Analysis}

To establish significance between paired samples, either a Student's $t$ test or Wilcoxon test were used (the latter when variables did not follow a normal distribution, as determined by the Shapiro-Wilk test). A $p$ value of $<0.05$ was defined as statistically significant. All statistical analyses were performed with SPSS (Statistical Package for the Social Sciences) version 25.0 for Windows. The last observation carried forward (LOCF) method was used to handle missing follow-up data. Data are reported as mean \pm standard deviation unless otherwise stated.

\section{Results}

\section{Patient Population}

Patient demographics and baseline characteristics are shown in Table 1 . In total, 44 eyes (31.8\% phakic, $63.6 \%$ pseudophakic, $4.5 \%$ aphakic) of 36 patients with persistent or recurrent DME were analyzed. At baseline, pa-

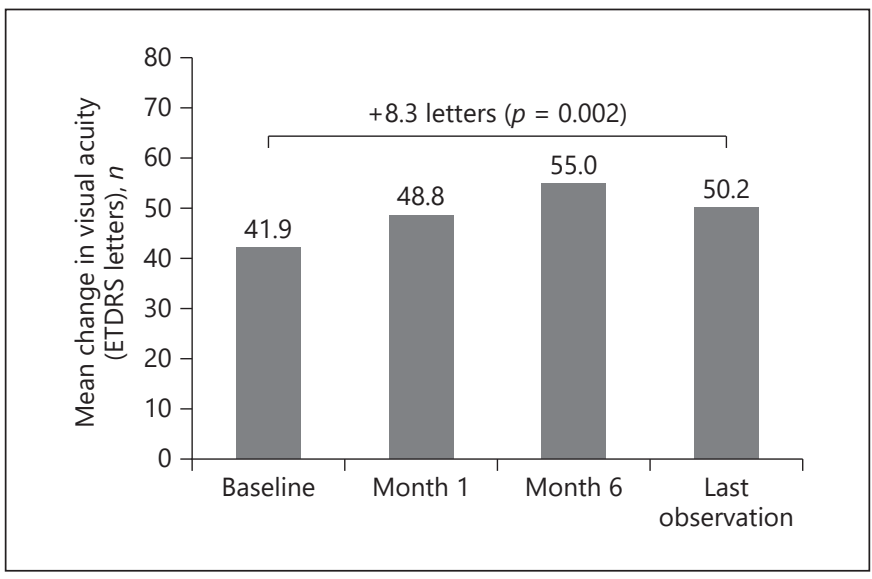

Fig. 1. Visual acuity mean change from baseline following FAc implantation.

tients had a mean age of 69.2 years, and approximately two-thirds (65.9\%) were male. Mean duration of DME was $3.3 \pm 1.9$ years, and patients were followed up for a mean period of $8 \pm 5.6$ months. Almost one-quarter $(22.7 \%)$ of eyes had undergone prior vitrectomy, and 8 eyes $(18.2 \%)$ needed IOP-lowering treatments. Other than dexamethasone, which all patients had received (mean 1.89 injections; range 1-4 injections), the most common previous treatment for DME was ranibizumab (administered to $53.5 \%$ of eyes).

\section{Efficacy}

At baseline, VA was $41.93 \pm 20.83$ letters. At month 1 after injection of the FAc intravitreal implant, the mean VA letter gain from baseline was +6.82 , and this increased to +13.02 letters $(p=0.005)$ at month 6 and $+8.3(p=$ 0.002 ) at LOCF (Fig. 1).

Similarly, significant improvements in CRT were noted following FAc intravitreal implant injection. At baseline, CRT was $542.81 \pm 149.56 \mu \mathrm{m}$, and this decreased by $71.81 \mu \mathrm{m}$ at month $1,170.77 \mu \mathrm{m}$ at month $6(p=0.001)$, and $121.46 \mu \mathrm{m}$ at LOCF ( $p=0.001)$ (Fig. 2).

A consistent mean decrease in MV $\left(-0.69 \mathrm{~mm}^{3}\right)$ from baseline $\left(10.09 \pm 1.99 \mathrm{~mm}^{3}\right)$ to LOCF was observed, although this did not reach statistical significance $(\mathrm{p}=$ 0.062) (Fig. 3).

\section{Safety}

At baseline, IOP was $14.3 \pm 4.81 \mathrm{~mm} \mathrm{Hg}$ and remained relatively stable at month $1(14.1 \pm 3.8 \mathrm{~mm} \mathrm{Hg}$; a change of $-0.25 \mathrm{~mm} \mathrm{Hg}$ from baseline) and month $6(15.2 \pm 7.1$ $\mathrm{mm} \mathrm{Hg} ;+0.88 \mathrm{mmHg}$ from baseline; $p=0.268$ ) (Fig. 4). 


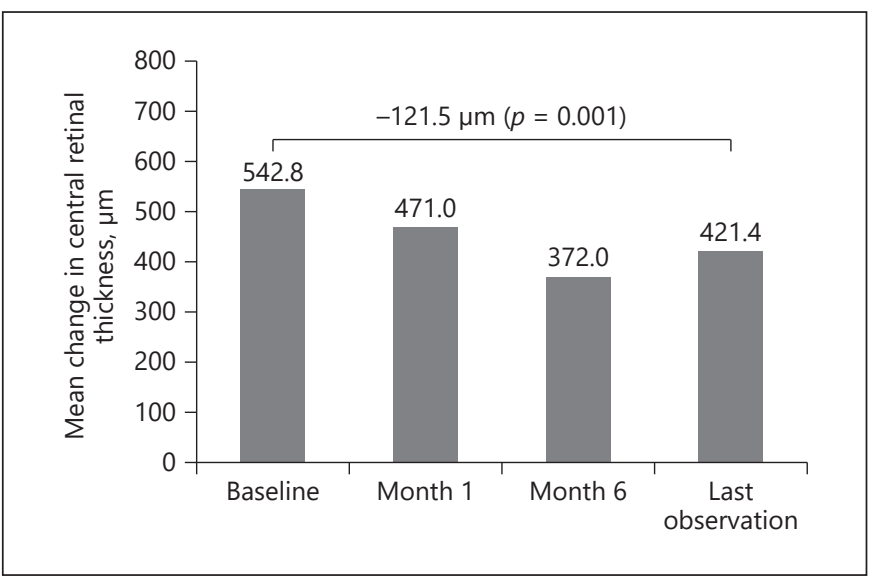

Fig. 2. Central retinal thickness mean change from baseline following FAc implantation.

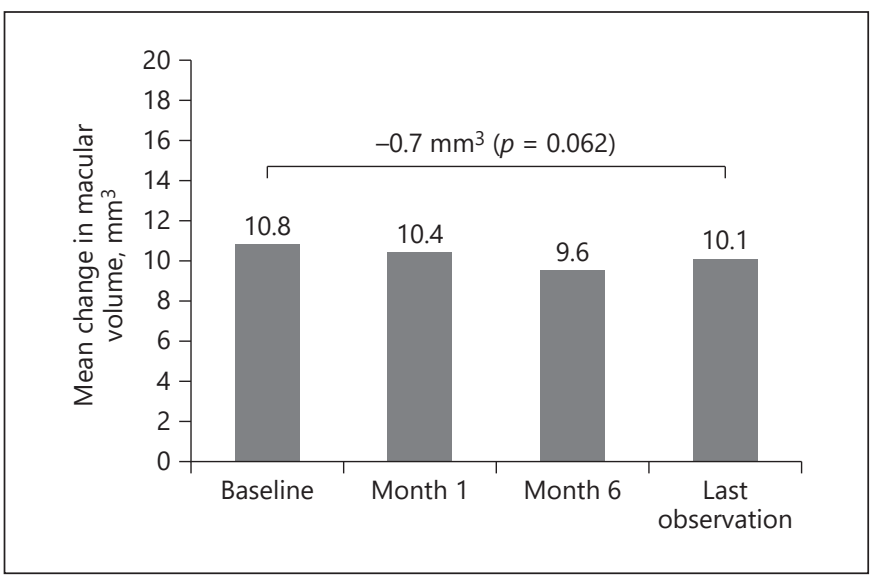

Fig. 3. Macular volume mean change from baseline FAc implantation.

LOCF revealed a small $(+1.86 \mathrm{~mm} \mathrm{Hg} ; p=0.036)$ change in pressure (Fig. 4). Figure 5 plots baseline IOP against IOP at LOCF for all patient eyes and shows 4 cases where IOP changed by $\geq 10 \mathrm{~mm} \mathrm{Hg}$ from baseline levels (also summarized in Table 2). In 2 of these cases IOP was managed with IOP-lowering drops prior to administration of the FAc implant and one of the patient eyes then underwent IOP-lowering surgery at month 6 . This patient was previously diagnosed with glaucoma. Of the remaining 2 cases, IOP was being managed with IOP-lowering drops, respectively, from months 12 and 15 . At baseline, in the total group, there were 8 cases where IOP was being managed with IOP-lowering drops (in the majority of cases $87.5 \%$ - with one to two drops of topical medication), and

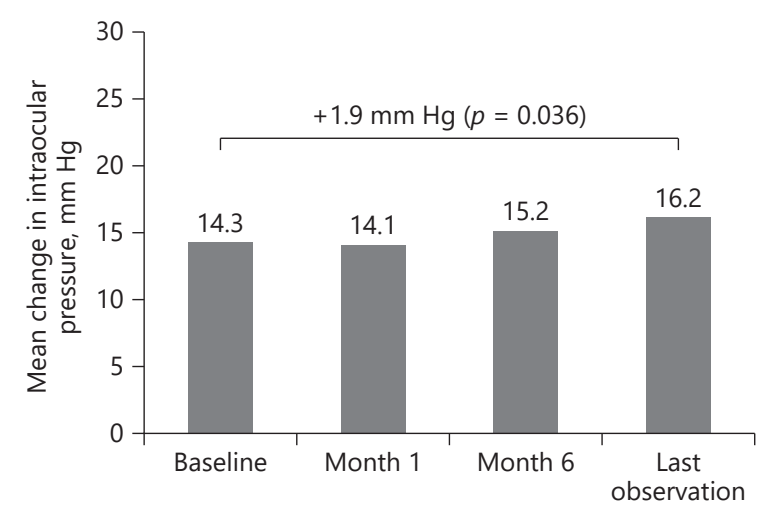

Fig. 4. Intraocular pressure mean change from baseline following FAc implantation.

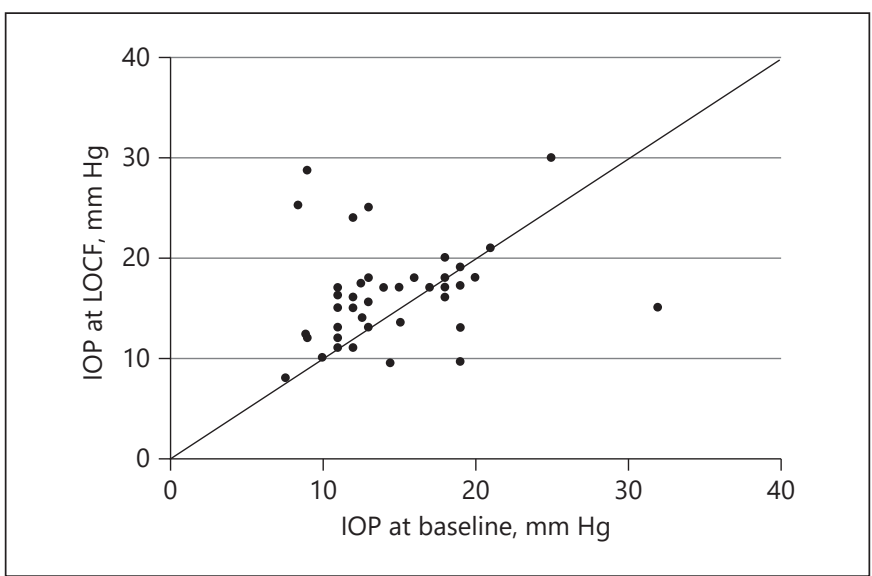

Fig. 5. Scatter plot of intraocular pressure (IOP) at baseline versus LOCF for all eyes.

Table 2. Mean IOP and treatments at baseline and LOCF $(n=44$ eyes)

\begin{tabular}{llc}
\hline Parameter & Baseline & LOCF \\
\hline IOP & & \\
$\geq 21 \mathrm{~mm} \mathrm{Hg}$ & 3 & 6 \\
$\geq 25 \mathrm{~mm} \mathrm{Hg}$ & 2 & 4 \\
$\quad \geq 30 \mathrm{~mm} \mathrm{Hg}$ & 1 & 1 \\
Change in IOP $\geq 10 \mathrm{~mm} \mathrm{Hg}$ from baseline & 0 & 4 \\
IOP drops & 8 & 11 \\
IOP surgery & 0 & 1 \\
\hline
\end{tabular}

Values are number of eyes. IOP, intraocular pressure. 
at LOCF there were 11 cases (i.e., 3 new cases during the follow-up period). On average, the time to first IOP-lowering drop was 3 months (range, 1-12 months) after injection of the FAc implant.

A total of 14 eyes (31.8\%) were phakic at baseline. During the period of follow-up 6 of these eyes (42.9\%) underwent cataract surgery which occurred on average at 6.7 months (range, 1-15 months) after injection of the FAc implant.

\section{Discussion}

In this retrospective, real-world study in patients with DME that persisted or recurred despite treatment, the injection of a single FAc intravitreal implant after an intravitreal injection of dexamethasone significantly improved VA and CRT outcomes. Safety signals were consistent with corticosteroid class effects, with small elevations in IOP that were controlled with topical medication in most cases. These results show the effectiveness and safety of the FAc intravitreal implant after a prior dexamethasone implant and are consistent with the previously findings reported [23]. Furthermore, the current findings are consistent with those reported in real-world clinical practices.

Previously reported RCTs show that the FAc intravitreal implant is efficacious in patients with persistent or recurrent DME, irrespective of lens status, for up to 36 months $[10,24,25]$. In real clinical practice, patients who received the FAc intravitreal implant had continuous and sustained exposure to treatment, irrespective of vitreous status, and achieved both functional and anatomical improvements [26]. While formal subgroup analyses were not done, outcomes in vitrectomized eyes in this study appear similar to those reported in the pivotal FAME studies, in which previously vitrectomized eyes were excluded [26]. Vitrectomy appears to increase both the distribution speed of an applied drug throughout the eye and the clearance of anti-VEGF agents and corticosteroids (triamcinolone); the latter effect can reduce drug exposure and impact on the success of anti-VEGF and corticosteroid treatment [26]. Such negative effects have not been observed to any clinically meaningful extent with the FAc intravitreal implant. Further real-world experience from the UK multicenter Medisoft audit study, the US Retrospective Chart Review in Patients Receiving ILUVIEN study (USER study), the ILUVIEN Registry Safety Study (IRISS), and the Pilot Study on the Effect and Safety of ILUVIEN ${ }^{\circledR}$ in Chronic Diabetic Macular Edema
Patients (RESPOND study) in Portugal, confirms the safety profile of the FAc intravitreal implant and supports the findings of the Fluocinolone Acetate for Macular Edema (FAME) studies [27-30]. In the Medisoft audit study, while overall IOP-related emergent events were observed at a similar frequency to those in the FAME studies, no adverse events were seen in patients with prior steroid exposure and no prior IOP events [27]. This finding supports the use of a prior steroid challenge to assess IOP responses and is the basis of the licensed indication in the US (i.e., the FAc implant is indicated for patients with DME who have been previously treated with a course of corticosteroids and did not have a clinically significant rise in IOP) [21, 30]. The mitigating effect of the requirement for prior steroid challenge on IOP responses is evident from the USER study: fewer IOP events were reported after FAc implantation in the USER study (in which all patients had received a course of prior corticosteroids) than in the FAME study [30]. Similarly, in the IRISS study, mean IOP for the overall population remained within the normal range throughout the follow-up period, and more than three-quarters of patients required no IOP-lowering therapy following treatment with the FAc implant [28]. These findings have been replicated in several other center-specific studies, even including patients with more advanced disease than those studied in the FAME trial [22, 31]. Regarding the presence of cataract, we note that in Portugal the use of the FAc implant is not restricted by lens status, unlike the UK, where only eyes with a pseudophakic lens can be treated. Hence, the percentage of phakic eyes in the current study were higher than in the IRISS study (i.e., 31.8 vs. $16.4 \%$, respectively) [28]. In our study, in the majority of cases (5 of 6 ) cataract surgery was conducted within the first year after the FAc implant was administered, providing new information on the timing of cataract extractions. Indeed, Yang et al. [32] showed that the decline in mean best-corrected VA associated with cataract development reached a minimum at around 18 months, suggesting that in real-world practice an earlier cataract extraction may be beneficial.

The administration of the FAc intravitreal implant soon after a suboptimal response to anti-VEGF injections (e.g., after 3-4 injections without positive anatomic gains [11]) may be considered earlier in the treatment of DME to avoid recurrences of edema, and could produce better long-term visual outcomes for patients [27]. Choosing when to switch to the FAc intravitreal implant can be highly individualized and influenced by several factors such as prior vitrectomy, which can decrease the durability of biological activity of anti-VEGF agents [11], as well 
as clinician choice [33]. In this study, the decisions to switch from the dexamethasone to the FAc implant included suboptimal response with dexamethasone, the desire for a less burdensome treatment, and the need for steroid challenge before receiving the FAc implant.

Nonadherence to treatment is a common problem in the management of patients with DME and leads to poorer outcomes $[34,35]$. The high frequency of anti-VEGF injections constitutes a heavy burden for patients and their families $[11,36]$. Patients must also attend consultations with various other specialists, which may be a further barrier to follow-up [36]. A single FAc intravitreal implant has been designed to deliver inflammation-suppressing FAc that lasts up to 3 years. Experience from the UK suggests that this helps to decrease the clinical, healthcare, and patient burdens of frequent injections and visits [37]. Reducing these burdens could improve the quality of life of patients and caregivers, as well as treatment compliance [37].

As well as offering effectiveness and clinical benefits, the FAc implant has also been found to reduce healthcare usage in the 12 months after implantation, compared with the preceding 12 months in the same patient. Total costs were higher in the 12 months after implantation due to the cost of the implant itself, but it is possible that the FAc implant may cost less than its alternatives over its 3-year lifespan [38]. In support of these findings, two cost analysis models from the UK found that over 3 years of treatment, a single FAc implant offers considerable cost savings compared with ranibizumab (in phakic and pseudophakic eyes) [39] and aflibercept monotherapy (in phakic eyes) [40]. However, whether these findings also apply to the healthcare system in Portugal is not known.

The limitations of this study included its retrospective design, which increases the potential for selection bias and confounding; the relatively small study sample, which limits the generalizability of the findings; and the use of the LOCF method when the mean follow-up period was relatively short (8 months). Additionally, as this was a real-world study, VA rather than best-corrected VA was measured, which may have underestimated the real functional gain.

\section{Conclusions}

The FAc intravitreal implant is an effective treatment option for patients previously treated with the short-acting dexamethasone implant. FAc significantly improves VA and edema in patients with recurrent DME, with safety signals consistent with corticosteroid class effects. Physicians and patients therefore have the choice to use the FAc implant earlier in the DME treatment process should they wish, and doing so may reduce the burden of the frequency of repeated injections for both patients and clinical staff.

\section{Acknowledgments}

Editorial support in the development of this manuscript was provided by Hayward Medical Communications and funded by Alimera Sciences in accordance with Good Publication Practice (GPP3) guidelines (www.ismpp.org/gpp3).

\section{Statement of Ethics}

The study was conducted in accordance with the ethical principles of the Declaration of Helsinki [41], International Conference on Harmonization Good Clinical Practice Guidelines [42], and all applicable country-specific regulatory requirements. The subjects gave their informed consent and the study protocol was approved by each local ethics committee.

\section{Disclosure Statement}

Dr. Vaz-Pereira reports advisory board honoraria from Bayer and Novartis and travel grants from Alimera, Allergan, Novartis, and Bayer. Dr. Castro-de-Sousa reports consulting honoraria from Zeiss and Alcon and travel grants from Alimera, Alcon, and Zeiss. Dr. Martins reports advisory board honoraria from Novartis and travel grants from Alimera, Allergan, and Bayer. Dr. Prates Canelas has received travel grants from Alimera, Allergan, Novartis, and Bayer. Dr. Reis has received travel grants from Alimera, Allergan, and Bayer. Dr. Sampaio, Dr. Urbano, and Dr, Kaku report no conflicts of interest. Dr. Nascimento reports advisory board honoraria and travel grants from Alimera, Allergan, Novartis, Bayer, and Bausch + Lomb. Dr. Marques-Neves reports advisory board honoraria from Novartis and travel grants from Alimera.

The authors have no proprietary or commercial interest in any materials discussed in this article.

\section{Funding Sources}

Medical writing and statistical assistance were funded by Alimera Sciences.

\section{Author Contributions}

All authors made substantial contributions to the conception, design, analysis, and interpretation of data for this study, and contributed to writing and revising the manuscript. All approved the final version. 


\section{References}

1 Browning DJ, Stewart MW, Lee C. Diabetic macular edema: evidence-based management. Indian J Ophthalmol. 2018 Dec;66(12): 1736-50.

2 Lee R, Wong TY, Sabanayagam C. Epidemiology of diabetic retinopathy, diabetic macular edema and related vision loss. Eye Vis (Lond). 2015 Sep;2(1):17.

3 Cavan D, Makaroff L, da Rocha Fernandes J, Sylvanowicz M, Ackland P, Conlon J, et al. The Diabetic Retinopathy Barometer Study: global perspectives on access to and experiences of diabetic retinopathy screening and treatment. Diabetes Res Clin Pract. 2017 Jul; 129:16-24.

4 Gonder JR, Walker VM, Barbeau M, Zaour N, Zachau BH, Hartje JR, et al. Costs and quality of life in diabetic macular edema: Canadian Burden of Diabetic Macular Edema Observational Study (C-REALITY). J Ophthalmol. 2014;2014:939315.

5 International Diabetes Federation. IDF diabetes atlas, 8 th edition. Brussels: International Diabetes Federation; 2017. Available from: http://www.diabetesatlas.org.

6 Schmit-Eilenberger VK. A novel intravitreal fluocinolone acetonide implant (Iluvien $\left({ }^{\circledR}\right)$ ) in the treatment of patients with chronic diabetic macular edema that is insufficiently responsive to other medical treatment options: a case series. Clin Ophthalmol. 2015 May;9: 801-11.

7 International Council of Ophthalmology. ICO guidelines for diabetic eye care. San Francisco: ICO; 2017.

8 Royal College of Ophthalmologists. Diabetic retinopathy guidelines. London: RCO; 2012.

9 Schmidt-Erfurth U, Garcia-Arumi J, Bandello F, Berg K, Chakravarthy U, Gerendas BS, et al. Guidelines for the Management of Diabetic Macular Edema by the European Society of Retina Specialists (EURETINA). Ophthalmologica. 2017;237(4):185-222.

10 Bailey C, Chakravarthy U, Lotery A, Menon G, Talks J. Clinical trial outcomes with Iluvien (fluocinolone acetonide) in the treatment of chronic diabetic macular oedema (DMO) are predictive of real-world outcomes after 24 months of continuous therapy. 8th World Congress on Controversies in Ophthalmology (COPHy); 30 March-1 April 2017; Madrid, Spain.

11 Eichenbaum DA, Buznego C, Weng CY, Dhoot DS, Wykoff CC, Sheth VS. When and how to incorporate steroids for persistent diabetic macular edema: a discussion of realworld treatment optimization strategies. Ophthalmic Surg Lasers Imaging Retina. 2018 Jul;49(7):S5-15.

12 Rezaei KA, Stone TW, editors. Global trends in retina survey 2016. Chicago: American Society of Retina Specialists; 2016. 1. Available from: https://www.asrs.org/content/documents/2016_global_trends_in_retina_survey_highlights_for_website_2.pdf.
13 Gillies MC, Sutter FK, Simpson JM, Larsson J, Ali H, Zhu M. Intravitreal triamcinolone for refractory diabetic macular edema: two-year results of a double-masked, placebo-controlled, randomized clinical trial. Ophthalmology. 2006 Sep;113(9):1533-8.

14 Martidis A, Duker JS, Greenberg PB, Rogers $\mathrm{AH}$, Puliafito CA, Reichel E, et al. Intravitreal triamcinolone for refractory diabetic macular edema. Ophthalmology. 2002 May;109(5): 920-7.

15 Edelman JL, Lutz D, Castro MR. Corticosteroids inhibit VEGF-induced vascular leakage in a rabbit model of blood-retinal and bloodaqueous barrier breakdown. Exp Eye Res. 2005 Feb;80(2):249-58.

16 Folkman J. Angiogenesis and apoptosis. Semin Cancer Biol. 2003 Apr;13(2):159-67.

17 Funatsu H, Yamashita H, Noma H, Mimura $\mathrm{T}$, Yamashita T, Hori S. Increased levels of vascular endothelial growth factor and interleukin-6 in the aqueous humor of diabetics with macular edema. Am J Ophthalmol. 2002 Jan;133(1):70-7.

18 Leopold IH. Nonsteroidal and steroidal antiinflammatory agents. In: Sears M, Tarkkanen A, editors. Surgical Pharmacology of the Eye. New York, NY, USA: Raven Press; 1985. pp. 83-133.

19 Nakano T, Ohara O, Teraoka H, Arita H. Glucocorticoids suppress group II phospholipase A2 production by blocking mRNA synthesis and post-transcriptional expression. J Biol Chem. 1990 Jul;265(21):12745-8.

20 Alimera Sciences. ILUVIEN 190 micrograms intravitreal implant in applicator. 2015. Available from: https://www.medicines.org. uk/emc/product/3061/smpc/print.

21 Alimera Sciences. ILUVIEN ${ }^{\circledR}$ (fluocinolone acetonide intravitreal implant) $0.19 \mathrm{mg}$ for intravitreal injection: highlights of prescribing information. 2016. Available from: https://alimerasciences.com/wp-content/uploads/2016/02/Prescribing-Information.pdf.

22 Fusi-Rubiano W, Blow RR, Lane M, Morjaria $\mathrm{R}$, Denniston AK. Iluvien ${ }^{\mathrm{TM}}$ (Fluocinolone Acetonide $0.19 \mathrm{mg}$ Intravitreal Implant) in the Treatment of Diabetic Macular Edema: A Review. Ophthalmol Ther. 2018 Dec;7(2): 293-305.

23 Singh P, Chedid A, Deuchler SK, Kohnen T, Müller M, Koch FH. The efficacy and safety outcomes of the $0.19 \mathrm{mg}$ fluocinolone acetonide implant after prior treatment with the 0.7 mg dexamethasone implant in patients with diabetic macular edema. Int Med Case Rep J. 2018 Oct;11:265-9.

24 Cunha-Vaz J, Ashton P, Iezzi R, Campochiaro P, Dugel PU, Holz FG, et al.; FAME Study Group. Sustained delivery fluocinolone acetonide vitreous implants: long-term benefit in patients with chronic diabetic macular edema. Ophthalmology. 2014 Oct;121(10):1892-903.

25 Wykoff CC, Chakravarthy U, Campochiaro PA, Bailey C, Green K, Cunha-Vaz J. Long- term Effects of Intravitreal $0.19 \mathrm{mg}$ Fluocinolone Acetonide Implant on Progression and Regression of Diabetic Retinopathy. Ophthalmology. 2017 Apr;124(4):440-9

26 Pessoa B, Coelho J, Correia N, Ferreira N, Beirão M, Meireles A. Fluocinolone Acetonide Intravitreal Implant $190 \mu \mathrm{g}\left(\right.$ ILUVIEN $\left.^{\circledR}\right)$ in Vitrectomized versus Nonvitrectomized Eyes for the Treatment of Chronic Diabetic Macular Edema. Ophthalmic Res. 2018;59(2):68-75.

27 Bailey C, Chakravarthy U, Lotery A, Menon G, Talks J, Medisoft Audit G; Medisoft Audit Group. Real-world experience with $0.2 \mu \mathrm{g} /$ day fluocinolone acetonide intravitreal implant (ILUVIEN) in the United Kingdom. Eye (Lond). 2017 Dec;31(12):1707-15.

28 Chakravarthy U, Taylor SR, Koch FH, Castro de Sousa JP, Bailey C. Changes in intraocular pressure after intravitreal fluocinolone acetonide (ILUVIEN): real-world experience in three European countries. Br J Ophthalmol. 2019 Aug; 103(8):1072-77.

29 Figueira J, Henriques J, Amaro M, Rosas V, Alves D, Cunha-Vaz J. A Nonrandomized, Open-Label, Multicenter, Phase 4 Pilot Study on the Effect and Safety of ILUVIEN ${ }^{\circledR}$ in Chronic Diabetic Macular Edema Patients Considered Insufficiently Responsive to Available Therapies (RESPOND). Ophthalmic Res. 2017;57(3):166-72.

30 Eaton A, Koh SS, Jimenez J, Riemann CD. The USER Study: A chart review of patients receiving a $0.2 \mu \mathrm{g} /$ day fluocinolone acetonide Implant for diabetic macular edema. Ophthalmol Ther. 2019 Mar;8(1):51-62.

31 Loewenstein A, Chakravarthy U, Bandello F. The $0.19 \mathrm{mg}$ fluocinolone acetonide intravitreal implant - a review on its use in diabetic macular oedema from the Association for Research in Vision and Ophthalmology Annual Meeting 2018. Eur Ophthalmic Rev. 2018; 12(2):88-97.

32 Yang Y, Bailey C, Holz FG, Eter N, Weber M, Baker C, et al.; FAME study group. Long-term outcomes of phakic patients with diabetic macular oedema treated with intravitreal fluocinolone acetonide (FAc) implants. Eye (Lond). 2015 Sep;29(9):1173-80.

33 Hall J. ILUVIEN in Diabetic Macular Edema: The Choice of Second-Line Corticosteroid Should Be Left to the Clinical Judgement of the Treating Physician. Ophthalmologica. 2018;239(4):234-7.

34 Ehlken C, Helms M, Böhringer D, Agostini HT, Stahl A. Association of treatment adherence with real-life VA outcomes in AMD, DME, and BRVO patients. Clin Ophthalmol. 2017 Dec;12:13-20.

35 Jansen ME, Krambeer CJ, Kermany DS, Waters JN, Tie W, Bahadorani S, et al.; Compliance Study Group. Appointment Compliance in Patients With Diabetic Macular Edema and Exudative Macular Degeneration. Ophthalmic Surg Lasers Imaging Retina. 2018 Mar; 49(3):186-90. 
36 Best AL, Fajnkuchen F, Nghiem-Buffet S, Grenet T, Quentel G, Delahaye-Mazza C, et al. Treatment efficacy and compliance in patients with diabetic macular edema treated with ranibizumab in a real-life setting. J Ophthalmol. 2018 Apr;2018:4610129.

37 Mourtzoukos S. The treatment of diabetic macular oedema (DMO) in UK real-life clinical practice with ILUVIEN (fluocinolone acetonide) - its impact on current clinical practice. Expert Rev Ophthalmol. 2017;12(2):957.

38 Holden SE, Currie CJ, Owens DR. Healtheconomic evaluation of fluocinolone acetonide 190 microg implant in people with diabetic macular edema. Curr Med Res Opin. 2017;33(sup2):45-52.
39 Quhill F, Beiderbeck A. Cost advantage of fluocinolone acetonide implant (ILUVIEN) versus ranibizumab in the treatment of chronic diabetic macular oedema. Glob Reg Health Technol Assess. 2017;4(1):e155-64.

40 Raman V. A cost analysis comparing continued 3-year aflibercept monotherapy versus a switch from aflibercept to the fluocinolone acetonide intravitreal implant in phakic patients with chronic diabetic macular edema. Expert Rev Ophthalmol. 2018;13(5):299307.
41 World Medical Association. WMA Declaration of Helsinki - ethical principles for medical research involving human subjects. 2013. Available from: https://www.wma.net/policies-post/wma-declaration-of-helsinki-ethical-principles-for-medical-research-involving-human-subjects/.

42 International Council for Harmonisation of Technical Requirements for Pharmaceuticals for Human Use. ICH Harmonised Guideline - Integrated Addendum to ICH E6(R1): Guideline for Good Clinical Practice E6(R2). 2016. Available from: https://www.ich.org/ fileadmin/Public_Web_Site/ICH_Products/ Guidelines/Efficacy/E6/E6_R1_Guideline. pdf. 